\title{
Dispersion and frequency: Is there any difference as regards their relation to $\mathbf{L} 2$ vocabulary gains? ${ }^{1}$
}

\author{
GEMA AlCARAZ-MÁRMOL* \\ Universidad de Castilla-La Mancha
}

Received: 25/6/2014. Accepted: 27/5/2015.

\begin{abstract}
Despite the current importance given to L2 vocabulary acquisition in the last two decades, considerable deficiencies are found in L2 students' vocabulary size. One of the aspects that may influence vocabulary learning is word frequency. However, scholars warn that frequency may lead to wrong conclusions if the way words are distributed is ignored. That is to say, it seems that not only the number of occurrences (frequency) might affect L2 vocabulary acquisition, but also the way occurrences are distributed (distribution). This relationship between these two factors is represented by the so-called Gries' index, known as dispersion. The present study aims to find out whether dispersion is more an accurate and reliable predictor for L2 vocabulary learning than frequency only.
\end{abstract}

KEYWORDS: Distributed learning, second language vocabulary acquisition, word dispersion, word frequency.

\section{RESUMEN}

A pesar de la gran importancia que hoy en día tiene la adquisición de vocabulario en segunda lengua, se siguen encontrando deficiencias importantes en el nivel léxico de L2 de los alumnos. La frecuencia se considera uno de los aspectos que puede influir el aprendizaje de vocabulario. Sin embargo, algunos investigadores advierten de que la frecuencia puede llevar a conclusiones erróneas si no se tiene en cuenta la distribución. Es decir, no solo el número de apariciones de una palabra (frecuencia) puede ser un factor determinante en la adquisición de vocabulario, sino también la manera en que esas apariciones están distribuidas en el tiempo (distribution). La relación entre distribución y frecuencia se conoce como el índice de Gries o dispersión. El presente estudio pretende explorar si la dispersión es un predictor más fiable del aprendizaje de vocabulario en L2 que la frecuencia.

PALABRAS CLAVE: Aprendizaje distribuido, adquisición de vocabulario en segunda lengua, dispersión, frecuencia.

*Address for correspondence: Gema Alcaraz Mármol. Universidad de Castilla-La Mancha, Departamento de Filología Inglesa, Edificio Sabatini, Facultad de Educación, Avenida Carlos III, s/n, 45071, Toledo, Spain; email: Gema.Alcaraz@uclm.es 


\section{INTRODUCTION}

The role of vocabulary in SLA has waxed and waned along the history of second language teaching, yet it has always been present in one way or another. Its importance started to grow firmly at the beginning of the $80 \mathrm{~s}$, when more and more studies started to proliferate. They highlighted the paramount role of vocabulary when learning a second language. In this sense, L2 scholars realized that vocabulary was no longer the Cinderella of studies in second language acquisition (Meara, 1980). What is more, vocabulary has proved to be a good predictor for both receptive (Laufer, 1992) and productive skills (Agustín Llach \& Jiménez Catalán, 2007; Golkar \& Yamini, 2007).

Despite the importance currently given to vocabulary, L2 students' level is far from what is expected in many cases. The results uncovered by Jiménez Catalán and Terrazas (2008) and by Jiménez Catalán and Moreno Espinosa (2005) represent this situation. These two studies estimated that Elementary school children acquired no more than 3 words per hour of instruction. This figure is roughly similar to the rate of acquisition found in LópezMezquita (2005). Her secondary school students presented a vocabulary size of around 940 receptive units in their last year of compulsory education ( $4^{\circ}$ ESO in the Spanish system). This figure corresponds to a rate of acquisition of about 2 words per contact hour. In the same line but in a different learning context, Quinn (1968) discovered that university students had a very low level in their second language despite it had been studied that language for several years. On average, students had only managed to acquire 1,000 word families after seven years of instruction, which does not even reach one word per hour.

This situation is still found nowadays and many scholars have explored how acquisition can be improved and which factors may affect it. From a holistic point of view, anything related to the phenomenon of L2 vocabulary acquisition can have a potential effect on learning. Nevertheless, there are two main underpinnings which are necessary for L2 vocabulary acquisition to make sense: the L2 item and the learner. If one of these two elements is missing, acquisition is virtually impossible. Each of these elements has different features, which make L2 vocabulary acquisition a complex process (Laufer, 1994). We can distinguish between factors that refer to the form and meaning of the L2 words (intralexical) and other type of factors that belong to the learner's condition (extralexical). Within the former we can find the learner's L1, word length or grammatical category. Oxford and Scarcella (1994) state that the fact that someone uses their L2 does not mean their L1 stops being active. The L1 activation happens also in experienced learners, even at the highest levels. Sunderman and Kroll (2006: 388) maintain that "acquiring proficiency in an L2 does not imply that the individual has acquired the ability to switch off the influence of the L1." In addition, the L2 itself can influence the process of acquisition. For instance, studies such as Coles (1982), Ellis and Beaton (1993) and Schmitt (2000) found that shorter words tend to be easier to retain than longer words. 
Regarding the second factor, that is grammatical category, several studies seem to confirm the hypothesis that nouns and adjectives are acquired more easily than verbs and adverbs (Philips, 1981; Ellis and Beaton 1993). On the contrary, Laufer (1994) argues that the learning difficulty attributed to the grammatical category of words is actually due to other intralexical factors such as phonological confusion.

As for the factors related to the learner's biological and psychological status, we can highlight age, gender or memory. In general terms, age has been one of the most widely explored in relation to SLA. Traditionally, the age factor has been given pride of place in syntax, morphology and phonology, but not so much in vocabulary. However, things have recently changed. Scholars tend to adopt the popular and widely used thought that the sooner you start learning a language the better, based on the Critical Period Hypothesis. In this line, Singleton (2001: 82) states that "there is a period of neurological language readiness with rigid limits outside of which language acquisition of any kind is difficult." As opposed to this idea, recent studies of English as L3 in Catalonia and the Basque Country claim that there is no significant difference in L3 vocabulary size between early and late starters (Muñoz, 2006).

Few studies have specifically dealt with the relationship between L2 vocabulary acquisition and gender. What is more, their aims, scope and conclusions differ strongly. Some comment on girls' superior performance (Jiménez Catalán \& Ojeda, 2008; Jiménez Catalán, 2003: Loulidi, 1990; Place, 1997), although some other scholars claim that it is males who outperform females (Lynn et al., 2005; Lin \& Wu, 2003; Edelenbos \& Vinje, 2000).

Aspects such as frequency and distribution should also be taken into consideration, although authors such as Laufer do not include them in her typology of affecting factors. Laufer argues that they do not appear in her typology of factors affecting L2 vocabulary learning, mainly because they are "usage factors dependent on the type of language input that the learner receives" (Laufer, 1994: 23). Yet, it does not mean that they are unimportant. In fact, frequency is one of the hotly discussed issues in L2 vocabulary acquisition. Word frequency can be defined as the number of times a word occurs in discourse. We can count the number of times a word occurs in a corpus of general discourse such as the British National Corpus, or in more specific compilations such as books or didactic materials. In the first case, frequency is labeled as 'general,' whereas in the second case frequency is referred to as 'specific'.

Many studies have shown the relationship between word frequency and word acquisition. Thus, general frequency has been proved to influence L2 vocabulary acquisition (Brown 1993; Meara, 1992). Meara (1992) designed a model of general frequency profile which seemed to be accurate in the way it characterized vocabulary growth. The model seemed to show that learners are sensitive to the general frequency of occurrence of the words they encounter. Meara (1992) supports this idea arguing that learners might know more of the high frequency words than they do of the lower frequency words. Meara's model 
has been tested and found to be robust. In 2006, 227 students participated in a study conducted by Milton (2009), where Meara's hypothesis about frequency was confirmed. L2 vocabulary was measured with a vocabulary recognition Yes/No test. The words tested were taken from frequency lists drawn up by Xue and Nation (1984). This study confirmed the idea that frequency bands and vocabulary size were related, and that the more frequent a word is the more likely it is to be learned.

The importance held by frequency is reflected in Nation's words: "when we look at texts our learners may have to read and conversations that are like ones that they may be involved in, we find that a relatively small amount of well-chosen vocabulary can allow learners to do a lot" (Nation, 2001: 9). In fact, it is expected that a relatively limited but highly frequent vocabulary allows learners to express themselves fairly well. Nowadays, the minimum threshold accepted for basic communication in English amounts to around 2000 word families. These families are not chosen at random. They are among the most frequent words in the general English discourse. Schmitt (2000: 142) argues that the 2000 most frequent word families "should still allow satisfying interactions with native speakers on topics focusing on everyday events and activities."

However, we should not forget that a large part of the L2 community learners acquire vocabulary in non-naturalistic environments, where the exposure to the L2 is limited in quantity and also in quality. The vocabulary input received by this type of learner is provided by the teacher and the didactic materials used in the classroom, and it may or may not coincide with frequency in general discourse. This is called 'specific frequency,' that is the number of times a word occurs in a specific context. Thus, "individual texts within each corpus can vary from one to another and from the overall frequency list which a corpus produces" (Milton, 2009: 25). That is why in this type of contexts specific frequency is considered of greater interest.

Nevertheless, and despite the high number of studies on frequency, to date there is no agreement on the number of occurrences that are necessary for a word to be acquired. Indeed, we do not even know whether all words need to be encountered the same number of times in order to be acquired. Horst et al. (1998) suggest that a word can only be acquired when it appears at least 6 times. In the same line, Rott (1999) compared three groups of learners with different number of exposures to the same words. Frequency of exposure was 2, 4 and 6 times. Those with the highest exposure to the word experienced the highest degree of acquisition. Other scholars such as Reyes (1999) or Webb (2007) state that acquiring a word is only possible if the word occurs at least 9 times. Some authors go even further and argue that it takes at least 20 occurrences for a word to become noticeable for a learner (Pigada \& Schmitt, 2006; Waring \& Takaki, 2003). We should not assume, however, that fewer encounters are useless. That is to say, it may be the case that encountering a word once or twice may not be enough for discerning its meaning or recalling its form, but it can trigger some degree of recognition (Hulstijn et al., 1996), which may eventually lead to acquisition. 
Studies have also explored the effect of frequency in delayed retention. It is stated that knowledge decreases dramatically after immediate acquisition and then gradually moves down, eventually getting established over time (Nagy et al., 1987), the first three months being critical for retention. Waring and Takaki's results (2003) show that learners only have $10 \%$ to $15 \%$ chance of remembering word meanings after three months, even after eighteen encounters.

However, it seems that L2 vocabulary teaching and learning should not be exclusively based on frequency. Despite its unquestionable relevance, relying just on frequency has several problems. Thus, if repetition is important, so is the distribution of that repetition. We agree with Gries $(2008,2009)$ and Leech et al. (2001) that specific frequency on its own can lead to wrong conclusions if distribution of elements is not taken into consideration. In Gries' words: "[...] it has become clear that for a variety of reasons frequencies of occurrence are not a perfect predictor of aspects of processing; [...] any kind of frequency effect will be ridden with noise and, hence, necessarily indirect" (Gries, 2009: 198). The author states that the number of occurrences plays a role in acquisition, but he adds that word occurrences should be related to the distribution of these occurrences, giving place to what is known as dispersion. ${ }^{2}$

To this respect, Ambridge et al. (2006: 175) hold that "given a certain number of exposures to a stimulus, or a certain amount of training, learning is always better when exposures or training trials are distributed over several sessions than when they are massed into one session." For instance, a word may occur from 10 to 12 times in each of ten very different registers, or it may occur 100 times in only one register, but the way these 100 occurrences are distributed may vary from one case to another.

Studies show that distributed learning has an effect on the learning of words. For instance, Childers and Tomasello (2002) found that four presentations distributed on different days were more effective than eight on a single day. In the same line, Schwartz and Terrell (1983) also observed that children named those items which were more frequently presented than those which were infrequently presented. The most interesting fact here is that constant distributed presentations led to higher retention than massed presentations did.

The studies above focus on first language acquisition. There are few studies about this issue which are framed within a second language context. Key factors in that type of approach include how much and at what rate vocabulary is introduced. These two aspects are intimately related to frequency of occurrence and distribution of items. As regards the former, there are many studies where frequency has been proved an influence for vocabulary learning. Studies such as Brown (1993) point towards a relevant effect of general frequency on vocabulary learning. This fact seems quite logical as words with higher frequency are expected to occur more often in discourse, and, at the same time, they provide learners with more chances to acquire them. 
However, as stated above a large part of the L2 community learns vocabulary in a nonnaturalistic environment. In these cases the L2 is usually learned within a formal context, where exposure is limited to the input provided by teachers and teaching materials. This exposure may or may not coincide with the frequency levels of general discourse, and it largely depends on the teaching materials used.

In this line, researchers analysed EFL materials and observed certain lack of systematicity in L2 vocabulary instruction (Alcaraz-Mármol, 2012; Scholfield, 1991). Nonsystematic introduction of vocabulary might be favored by the methodological trend that is currently followed in most didactic materials, resulting in a highly unprincipled selection process for the words in a textbook (Scott, 2005). Nonetheless, the most worrying fact is not the absence of a regular pattern, but the absence of a rationale behind the introduction of specific words. Put it another way, it might be the case that a pattern of distribution is not systematic, but it has a teaching rationale behind, which does not seem to be the case in most analysed materials (Scholdfield 1991; Scott, 2005).

Word dispersion has been explored by authors such as Lyne (1985) or Zhang et al. (2004). They have proposed different measures that involve both frequency and distribution, but they are found too complicated to use, or they are not language specific and are not easy to adapt to the linguistic context. Alternatively to these proposals, Gries suggests what he calls the deviation of proportions, hereafter DP. It is a measure of dispersion which "is conceptually simpler and more versatile than many competing measures" (Gries, 2008: 197).

Yet, few studies have really found out the role of dispersion in second language acquisition, and how it relates to frequency as regards L2 vocabulary acquisition. He holds that: "[...] if dispersion plays the role some corpus linguists have argued, then controlling for frequency alone may turn out to be insufficient unless dispersion is considered at the same time" (Gries, 2009: 200).

Therefore, the aim of the present study is to find out whether there is a difference between specific frequency and a measure of dispersion such as distribution of proportions (DP) as regards prediction of L2 vocabulary acquisition.

\section{RESEARCH QUESTIONS}

The research questions I will seek to answer in this study are:

1. Does the DP index have an effect on L2 vocabulary acquisition?

2. Is the DP index a better predictor for L2 vocabulary acquisition than specific frequency? 


\section{METHODOLOGY}

\subsection{Participants}

The group of participants for this study consists of 20 middle-class students (13 girls and 7 boys) of English as a Foreign Language in their fourth year of Primary Education with ages between 9 and 10. They had a Spanish or Latino origin, but all of them were born in Spain. None of them had extra lessons or studied any other language. At the moment the study was carried out, the students had received around 350 hours of instruction, equating to an elementary level of English. They received two hours and forty-five minutes of formal English instruction per week. They all belonged to the same public school in Murcia, spoke Spanish as their mother tongue and could not speak any other language.

In the second Spanish cycle of Elementary Education English is taught as a compulsory subject, it being basically conceived at the word level. In this particular context input was mainly and almost exclusively provided by the coursebook, which was accurately followed by the teacher. Additionally, the teacher normally used the Spanish language as a way to explain words, and sometimes she translated them.

\subsection{Words}

The selected words appeared in English Adventure (Longman, 2011), the coursebook which participants followed during the English lessons at school. English Adventure is based on a Communicative-Functional approach, and contains 2416 tokens and 500 types, out of which 158 are considered target words. Thirty words were chosen among the target vocabulary that was introduced to students, which means almost $20 \%$ of the target vocabulary introduced by the coursebook. We focused on units 1,2, and 3, to be developed during the first term of the academic year. A number of characteristics guided the selection of the target words: they were target words in the coursebook; cognates such as chocolate or colour were avoided; and different word categories were included - nouns, adjectives and verbs. It is also important to highlight that the teacher accurately followed the coursebook and did not introduce any other materials. A pre-test confirmed that target words were unknown to the students (see 3.3 below).

The number of occurrences of each target word across the three units ranged from 3 to 13. Words were grouped into different categories according to the number of times they occurred in the corpus. In this case 10 items appeared from 3 to 6 times, 11 items appeared from 7 to 10 times and 9 items occurred over 10 times (see Table 1). 


\begin{tabular}{|l|l|l|l|l|l|}
\hline Word & $\begin{array}{l}\text { Specific } \\
\text { frequency }\end{array}$ & Word & $\begin{array}{l}\text { Specific } \\
\text { frequency }\end{array}$ & Word & $\begin{array}{l}\text { Specific } \\
\text { frequency }\end{array}$ \\
\hline Bathroom & 11 & Jumper & 10 & Tie & 10 \\
\hline Bell & 7 & Kitchen & 11 & Tight & 6 \\
\hline Biscuit & 12 & Milk & 10 & Trousers & 10 \\
\hline Call & 4 & Roof & 8 & Vest & 11 \\
\hline Clean & 6 & Shirt & 3 & Walk & 10 \\
\hline Dirty & 12 & Shocks & 5 & Wall & 13 \\
\hline Garden & 5 & Shop & 12 & Watch & 9 \\
\hline Hat & 11 & Skirt & 6 & Wear & 5 \\
\hline Huge & 8 & Sweet & 7 & Wonderful & 7 \\
\hline Juice & 12 & Tidy & 9 & Zip & 4 \\
\hline
\end{tabular}

Table 1. Specific frequencies of target words

Gries' Deviation of Proportions (DP) was calculated for each target word according to its dispersion in the coursebook. The three steps provided by Gries (2009) were taken in order to compute the DP of each word. The first one consisted of determining the sizes of each of the corpus parts. In this case the corpus had three parts - each part corresponding to one didactic unit. They were normalized against the overall corpus size -in this case it was the coursebook - and corresponded to expected percentages which took differently sized corpus parts into consideration. In the second place, frequency of occurrence in each corpus part was taken into account. This frequency was normalized against the overall number of word occurrences which gave place to an observed percentage. Finally, we needed to compute all pairwise absolute differences of observed and expected percentages, add them up, and divide the result by two. These three steps resulted into the word DP index. The closer DP is to zero, the more regular word dispersion is (Table 2). The DP indices in this study ranged from 1.10 to 5.30 .

\begin{tabular}{|l|l|l|l|l|l|}
\hline Word & DP & Word & DP & Word & DP \\
\hline Milk & 5.3 & Skirt & 3 & Biscuit & 2 \\
\hline Hat & 4.66 & Tight & 3 & Clean & 2 \\
\hline Sweet & 4.66 & Bell & 2.66 & Dirty & 2 \\
\hline Walk & 4.66 & Call & 2.66 & Shirt & 2 \\
\hline Trousers & 4.32 & Kitchen & 2.66 & Watch & 2 \\
\hline Jumper & 3.66 & Roof & 2.66 & Huge & 1.82 \\
\hline Tie & 3.66 & Zip & 2.66 & Garden & 1.66 \\
\hline Wear & 3.32 & Bathroom & 2.65 & Wall & 1.66 \\
\hline Juice & 3 & Socks & 2.32 & Wonderful & 1.66 \\
\hline Shop & 3 & Vest & 2.32 & Tidy & 1.1 \\
\hline
\end{tabular}

Table 2. DP indices of the target words

\subsection{Data collection instruments}

Students had received over 300 hours of English instruction. Consequently, a pre-test was necessary. Students were presented a list with the Spanish equivalents of the L2 target words. The pre-test consisted of providing the L2 equivalents for L1 terms. After instruction was finished, the same test was administered in the form of a post-test. 
Both the pre-test and the post-test adopted the translation format and focused on recalling the written word form. Words were arranged alphabetically and each of them was accompanied by a dotted line where the L2 equivalent was expected to be provided. According to Takala (1984: 146), "the best pay-off between validity, reliability and practicality is shown by test types which ask students to write L 2 or L1 equivalents to written decontextualized stimulus words." Tests based on providing equivalents to words in another language are considered to be reliable instruments for L2 vocabulary acquisition (Read, 2000). In fact, Nation (2001) encourages the use of the L1 in the vocabulary testing on participants with a low level of L2, as it is the case here. The author holds that the attitude of rejecting translation for vocabulary assessment "is quite wrong [because] translation is one of a number of means of conveying meaning and in general is no better or worse than the use of pictures, real objects, definitions, L2 synonyms and so on" (Nation, 2001: 351). That is why it was decided to resort to the L1 as a stimulus.

Scoring for the L1-L2 productive pre-test and post-test was based on a dual system. Minor spelling mistakes were not penalized unless they distorted the meaning of the word, or the word form was not understandable. For instance, both grass and glass exist in English but the use of ' $r$ ' instead of ' $l$ ' transforms the word into a completely different item with a different meaning. The second condition where the answer is penalized holds if the student writes slags instead of glass.

\subsection{Data collection procedure}

As regards the procedure, tests were administered to students in an intact fourth-year class group by the researcher in the presence of the teacher. It is worth noting that both the pre-test and the post-test were timed and that the provided resources were printed materials. Specifically, 30 minutes were given for taking each test. The pre-test was administered two months before the beginning of the lessons and the post-test was administered immediately after the three didactic units were finished.

\subsection{Data analysis}

In order to know whether there is a significant difference between specific frequency and the DP as regards their effect on vocabulary acquisition, a multivariate regression was carried out. The statistical program SPSS (version 21.0) was used for data analysis. The dependent variable in this case corresponds to vocabulary acquisition -represented by the post-test-, whereas specific frequency and the DP index hold as independent variables. 


\section{RESULTS}

As for the first question, that is, whether word dispersion has an effect on L2 vocabulary acquisition, the multiple regression analysis shows that there is a statistically significant relationship between the DP index and vocabulary learning. That is to say, the more regularly dispersed words were, the more students could recall them in a test. Significance is statistically significant at .000 for the DP, which means that this relationship is highly considerable (see Table 3).

\begin{tabular}{|c|c|c|c|c|c|}
\hline Model & Non stan & d coefficients & Typical coefficients & $\mathrm{t}$ & Sig \\
\hline & $\mathrm{B}$ & Standard deviations & Beta & & \\
\hline $\begin{array}{cc}1 & \text { (Constant) } \\
\text { DP } \\
\text { Specific Frequency }\end{array}$ & $\begin{array}{l}16.775 \\
-2.195 \\
-.178\end{array}$ & $\begin{array}{c}1.582 \\
.396 \\
.146\end{array}$ & $\begin{array}{l}-.712 \\
-.157\end{array}$ & $\begin{array}{l}10.604 \\
-5.544 \\
-1.226\end{array}$ & $\begin{array}{l}.000 \\
.000 \\
.231\end{array}$ \\
\hline
\end{tabular}

Table 3. Multivariate regression

Table 4 shows different word frequencies and DPs together with acquisition after instruction. Column SP stands for the specific frequency of each word. DP stands for the word index of dispersion. The column labeled 'acquisition' contains the number of students who, according to the post-test, have acquired the words. We can observe that there are words such as "wall" with low DP -that is, they are regularly distributed- as well as with high frequency of occurrence along the three didactic units analyzed. They are regularly dispersed and they occur many times. Words in this line do not present high level of acquisition. In turn, words such as "sweet" have irregular distribution and, in addition, its frequency is very low. Given this situation, it is expected to observe low degree of acquisition in these cases.

\begin{tabular}{|l|c|c|c|l|c|c|c|}
\hline Word & SP & DP & Acquisition & Word & SP & DP & Acquisition \\
\hline Bathroom & 11 & 2.65 & 10 & Socks & 5 & 2.32 & 9 \\
\hline Bell & 7 & 2.66 & 7 & Shop & 12 & 3 & 8 \\
\hline Biscuit & 12 & 2 & 13 & Skirt & 6 & 3 & 7 \\
\hline Call & 4 & 2.66 & 11 & Sweet & 7 & 4.66 & 5 \\
\hline Clean & 6 & 2 & 18 & Tidy & 9 & 1.1 & 12 \\
\hline Dirty & 12 & 2 & 11 & Tie & 10 & 3.66 & 11 \\
\hline Garden & 5 & 1.66 & 10 & Tight & 6 & 3 & 8 \\
\hline Hat & 11 & 4.66 & 10 & Trousers & 10 & 4.32 & 8 \\
\hline Huge & 8 & 1.82 & 10 & Vest & 11 & 2.32 & 12 \\
\hline Juice & 12 & 3 & 8 & Walk & 10 & 4.66 & 9 \\
\hline Jumper & 10 & 3.66 & 6 & Wall & 13 & 1.66 & 15 \\
\hline Kitchen & 11 & 2.66 & 8 & Watch & 9 & 2 & 11 \\
\hline Milk & 10 & 5.3 & 6 & Wear & 5 & 3.32 & 5 \\
\hline Roof & 8 & 2.66 & 8 & Wonderful & 7 & 1.66 & 12 \\
\hline Shirt & 3 & 2 & 9 & Zip & 4 & 2.66 & 7 \\
\hline
\end{tabular}

Table 4. Word acquisition 
The most interesting examples are words with low DP and low frequency, and words with high DP and high frequency. In the first case, even though some words occur few times, they are acquired by a relatively high percentage of the students, that is, low frequency does not prevent target words from being acquired. By contrast, most words with high DP -that is irregularly distributed- and high frequency are not acquired by a significant number of students. It points to the idea that frequency has a lower effect than distribution in relation to acquisition.

As for the second question we wondered whether the DP is a better predictor than specific frequency. Results show that the frequency effect is not statistically significant in our study. That is to say, we could not find a relationship between the number of times a word appears and its acquisition (see Figure 1). Consequently, the answer to the second question is positive. Word dispersion -represented by the DP- seems to be a better predictor than specific frequency (see Figure 2).

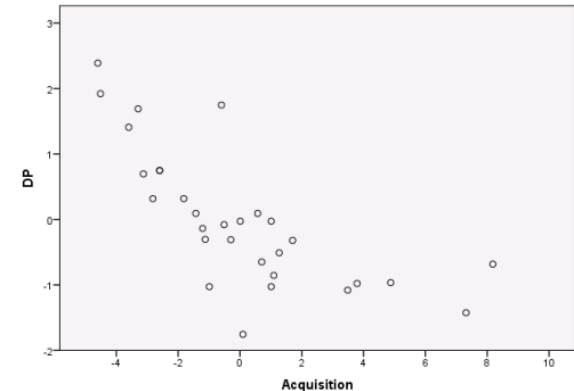

Figure 1. DP effect on acquisition.

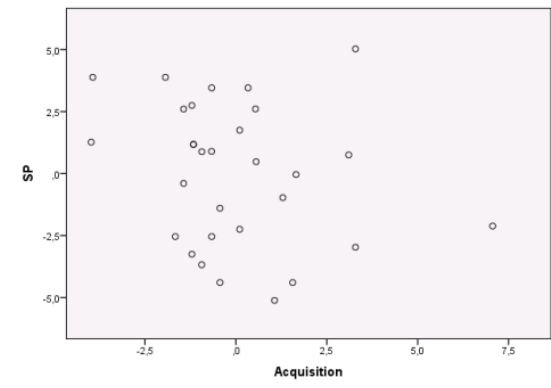

Figure 2. Specific frequency effect on acquisition

\section{DISCUSSION}

In the light of these results, it appears that distribution has an important role in L2 vocabulary acquisition and does make a difference in comparison to specific frequency. To this respect, a study by Alcaraz-Mármol (2012) shows that those words which were more regularly distributed were acquired by more students than others that were not so regularly introduced. Some scholars such as Milton (2009) and Orosz (2009) have analyzed the language teaching system in countries such as Greece or Hungary -with principled vocabulary introduction- in comparison with others such as France or UK where introduction seems to be more arbitrary. Milton (2009) observed that most learners who studied English within the Greek system showed good and regular progress in their vocabulary knowledge. Another example is the study by Orosz (2009). Her conclusions after observing the Hungarian state school system 
seemed to be similar to Milton's. Yet, Milton (2006) goes further by warning about the little progress in vocabulary knowledge among students from France or the UK, where vocabulary teaching is based on massed introduction, that is, without any type of order or rationale behind.

All these outcomes are in line with Gries' idea that frequency alone can lead to wrong conclusions (Gries, 2008). Already at the end of the eighties and the beginning of the nineties, some scholars intuitively suggested the systematic introduction as an alternative to the "unstable lexical economy" (Scholfield, 1991: 1). This fact is reflected in many foreign language coursebooks, which are characterized by the lack of a funded and systematic introduction and distribution of vocabulary (Alcaraz-Mármol, 2010, 2011). Scholfield (1991) and Gairns and Redman (1986) recommended the introduction of 9 words per hour of instruction in the first case, and from 8 to 12 words per hour in the second case, depending on the students' level.

There are two possible reasons why specific frequency did not turn out to be better for acquisition than dispersion here. The first one points to the insufficient number of occurrences of the words. None of the words in the study appears more than 13 times. In fact, recent studies such as Waring and Takaki (2003) or Pigada and Schmitt (2006) show that it might take at least 20 occurrences for a word to become noticeable to a learner.

Consequently, more occurrences might have shown a more relevant role of frequency. The second reason points to the type of test that students had to do. Word knowledge was checked by means of a productive test. As stated above, the reason was that students might have some receptive knowledge about some of the words, as they had already received over 300 hours. A productive test was chosen because it implied higher difficulty than a receptive test. A productive test requires recalling the $\mathrm{L} 2$ form, whereas a receptive test implies less cognitive effort as it consists of recognizing a form. In Scholfield's words: "if the task is simply to remember one meaning of the new word [...] more items may be mastered than if the task is to remember the exact spelling of the word and be able to use it" (Scholfield, 1991: 13). It might have been the case that the frequency effect could have been greater as regards receptive knowledge.

It is important to clarify, though, that encountering a word once or twice may not be enough for recalling its form, but we do not deny the idea that even one or two occurrences can trigger some degree of recognition (Hulstijn et al., 1996). As Nagy and Herman claim, "even a single encounter with a word [might push it up] a little big higher on the scale of knowledge" (Nagy \& Herman, 1987: 25).

The predictive effect of distribution is especially relevant in a foreign language context, where contact with the target language is usually confined to formal instruction. That is why we should make an effort and optimize the students' limited time of exposition to the foreign language. In this sense, distribution is a key factor. Distribution may not be so relevant in a 
naturalistic context, since the contact with the target language is unlimited, and consequently frequency may have a more important role.

Admittedly, this study with a sample of 20 students may not lead us to strong conclusions. A more representative sample of participants could affect the study outcomes. In the same line, the number of analyzed words may not be big enough. The very nature of the words could have altered the results. That is to say, no adverbs have been included and the number of nouns, verbs and adjectives is not exactly the same.

Nonetheless, the results obtained in this study can help the design of second language teaching materials. In fact, coursebooks are normally characterized by lack of systematicity as regards the introduction and treatment of target vocabulary. The coursebook adopts a particularly relevant role in foreign language contexts, where it is one of the most important sources of input. Several studies show the arbitrariness found in most coursebooks with respect to the amount of target vocabulary and the number of target words introduced per lesson or didactic unit. Scholfield (1991) and Alcaraz-Mármol (2011) used vocabulary rate plots to know the rate at which vocabulary was introduced. In both cases considerable differences were found between coursebooks and between one didactic unit and another within the same course.

These two studies show the different philosophy and criteria behind the way vocabulary is treated. Hence, courses targeting the same audience may display considerable differences in their patterns of vocabulary distribution. For instance, in Alcaraz-Mármol (2011) one of the coursebooks had a clear increasing tendency in the number of target words introduced per didactic unit, whereas she found the opposite in another coursebook of the same level, where the pattern of introduction was decreasing towards the end of the academic year.

It is far from our intention to discount frequency, but it is necessary to further explore how to exploit dispersion in the context of L2 vocabulary teaching and learning. That is to say, once dispersion seems to play a role in learning, the next step is to transform the former into figures, so that we can answer questions such as how many words per hour of instruction, or at what rate vocabulary should be introduced.

\section{FINAL REMARKS}

The present study seems to show that a measure of dispersion is more accurate than specific frequency when predicting vocabulary acquisition. Accordingly, the statement that the higher number of word occurrences the higher number of chances to acquire a word should be finetuned. In other words, acquisition is not just a question of how much, but also at what rate. That is why a measure of dispersion is recommended instead of just frequency counting when making statements about L2 vocabulary acquisition. Yet, these results are preliminary, since 
the number of words and participants is limited and further research has to be done in order to reach solid conclusions.

\section{NOTES}

1. "Learning" and "acquisition" are used interchangeably in this paper.

2. The terms "dispersion" and "distribution" are understood as the same phenomenon, the first being the way Gries conceptualizes word distribution.

\section{REFERENCES}

Agustín Llach, P. \& Jiménez Catalán, R. (2007). Lexical reiteration in EFL young learners' essays: Does it relate to the type of instruction? IJES, 7, 85-104.

Alcaraz-Mármol, G. (2012). Systematic introduction of vocabulary and its effect on acquisition: Primary Education students of English as a Foreign Language. Porta Linguarum, 18, 149-159.

Alcaraz-Mármol, G. (2010). The role of frequency in the Elementary Foreign Language classroom. Malaysian Journal of ELT Research, 6, 68-194.

Alcaraz-Mármol, G. (2011). Vocabulary input in classroom materials: Two EFL coursebooks used in Spanish schools. Revista Española de Lingüística Aplicada, 24, 9-28.

Ambridge, B., Theakston, A., Lieven, E. \& Tomasello, M. (2006). The distributed learning effect for children's acquisition of an abstract syntactic construction. Cognitive Development, 21, 174193.

Brown, C. (1993). Factors affecting the acquisition of vocabulary. In T. Huckin, M. Haynes \& J. Coady (Eds.), Second Language Reading and Vocabulary (pp. 263-286). New Jersey: Ablex.

Childers, J. B. \& Tomasello, M. (2002). Two-year-olds learn novel nouns, verbs, and conventional actions from massed or spaced exposures. Developmental Psychology, 38, 967-978.

Coles, M. (1982). Word Perception, First Language Script and Learners of English as a Second Language. MA project, Birbeck College, University of London.

Edelenbos, P. \& Vinje, M. (2000). The assessment of foreign language at the end of the primary (elementary) education. Language Testing, 17, 144-162.

Ellis, N. \& Beaton, A. (1993). Psycholinguistic determinants of Foreign Language vocabulary learning. Language Learning, 43, 559-617.

English Adventure (2011). London: Longman.

Gairns, R. \& Redman, S. (1986). Working with Words: A Guide to Teaching and Learning Vocabulary. Cambridge: Cambridge University Press.

Golkar, M. \& Yamini, M. (2007). Vocabulary, proficiency and reading comprehension. The Reading Matrix, 7, 88-112.

Gries, S. (2008). Dispersions and adjusted frequencies in corpora. International Journal of Corpus Linguistics, 13, 403-437.

Gries, S. (2009). Dispersions and adjusted frequencies in corpora: Further explorations. In S. Gries, S. Wulff \& M. Davies (Eds.), Corpus-linguistic Applications: Current Studies, New Directions (pp. 197-212). Amsterdam: Rodopi.

Horst, M., Cobb, T. \& Meara, P. (1998). Beyond a Clockwork Orange: Acquiring second language vocabulary through reading. Reading in a Foreign Language, 11, 207-223.

Hulstijn, J., Hollander, M. \& Greidanus, T. (1996). Incidental vocabulary learning by advanced foreign language students: The influence of marginal glosses, dictionary use, and reoccurrence of unknown words. The Modern Language Journal, 80, 327-339.

Jiménez Catalán, R. M. (2003). Sex differences in L2 vocabulary learning strategies. International Journal of Applied Linguistics, 13, 54-77.

Jiménez Catalán, R. M. \& Moreno Espinosa, S. (2005). Using Lex30 to measure the L2 productive vocabulary of Spanish primary learners of EFL. Vial, 13, 27-44. 
Jiménez Catalán, R. M. \& Ojeda, J. (2008). The English vocabulary of girls and boys: Evidence from a quantitative study. In K. Harrington (Ed.), Gender and Language Research Methodologies (pp. 120-132). New York: Palgrave Macmillan.

Jiménez Catalán, R. M. \& Terrazas, M. (2008). The receptive vocabulary of English in Foreign Language young learners. IJES, 2, 201-215.

Laufer, B. (1992). Reading in a foreign language: How does L2 lexical knowledge interact with the reader's general academic ability? Journal of Research in Reading, 2, 95-103.

Laufer, B. (1994). The lexical profile of second language writing: Does it change over time? RELC Journal, 25, 21-33.

Leech, G. N., Rayson, P. \& Wilson, A. (2001). Word Frequencies in Written and Spoken English: Based on the British National Corpus. London: Longman.

Lin, J. \& Wu, F. (2003). Differential performance by gender in foreign language testing. Poster session presented at the Annual Meeting of NCME, Chicago, April 2003.

López-Mezquita, M. T. (2005). La evaluación de la dimensión léxica a nivel receptivo: un marco para el diseño de instrumentos de medida. Perspectivas interdisciplinares de la Lingüística Aplicada. RESLA, 19, 381-390.

Loulidi, R. (1990). Is language learning really a female business? Language Learning Journal, 39, 40-43.

Lyne, A. (1985). Dispersion. In A. Lyne (Ed.), The Vocabulary of French Business Correspondence: Word Frequencies, Collocations and the Problems of Lexicometric method (pp. 101-124). Paris: Slatkine-Champion.

Lynn, R., Fergusson, D. \& Horwood, L. J. (2005). Sex differences on the WISC-R in New Zealand. Personality and Individual Differences, 39, 103-114.

Meara, P. (1980). Vocabulary acquisition: A neglected area of language learning. Language Teaching and Linguistics: Abstracts, 15, 221-246.

Meara, P. (1992). EFL Vocabulary Tests. Swansea: Lognostics.

Milton, J. (2006). Language lite. Learning French vocabulary in school. Journal of French Langue Studies, 16, 187-205.

Milton, J. (2009). Measuring Second Language Vocabulary Acquisition. Bristol: Multilingual Matters.

Muñoz, C. (2006). Age and the Rate of Foreign Language Learning. Clevedon. Buffalo, Toronto. Multilingual Matters Publications.

Nagy, W. E. \& Herman, P. A. (1987). Breadth and depth of vocabulary knowledge: Implications for acquisition and instruction. In G. McKeown \& M. E. Curtis (Eds.), The Nature of Vocabulary Acquisition (pp. 19-35). New Jersey: LEA.

Nation, P. (2001). Learning Vocabulary in another Language. Cambridge: Cambridge University Press.

Orosz, A. (2009). The growth of young learners' English vocabulary size. In M. Nikilov (Ed.), Early Learning of Modern Foreign Languages (pp. 181-194). Bristol: Multilingual Matters.

Oxford, R. \& Scarcella, R. (1994). Second language vocabulary learning among adults: State of the art in vocabulary instruction. System, 22, 231-243.

Philips, T. (1981). Difficulties in Foreign Language Vocabulary Learning and a Study of some of the Factors Thought to be Influential. MA Project, Birbeck College, University of London.

Pigada, M. \& Schmitt, N. (2006). Vocabulary acquisition from extensive reading: A case study. Reading in a Foreign Language, 18, 1-28.

Place, J. (1997). Boys will be boys - boys under achievement in MFL. Language Learning Journal, $16,3-10$.

Quinn, G. (1968). The English Vocabulary of some Indonesian University Entrants. Salatiga: English Department Monograph IKIP Kristen Satya Watjana.

Read, J. (2000). Assessing Vocabulary. Cambridge: Cambridge University Press.

Reyes, M. J. (1999). Incidencia de la variable 'curso' en el aprendizaje léxico. In Actas del XI Congreso Internacional de la Asociación de Lingüistica y Filología de la América Latina. ULPGC, Las Palmas de Gran Canaria, 1675-1681.

Rott, S. (1999). The effect of exposure frequency on intermediate language learners' incidental vocabulary acquisition and retention through reading. Studies in Second Language Acquisition, 21, 589-619.

(C) Servicio de Publicaciones. Universidad de Murcia. All rights reserved. IJES, vol. 15 (2), 2015, pp. 1-16 Print ISSN: 1578-7044; Online ISSN: 1989-6131 
Schmitt, N. (2000). Vocabulary in Language Teaching. Cambridge: Cambridge University Press.

Scholfield, P. (1991). Vocabulary rate in coursebooks - living with an unstable lexical economy. In Proceedings of 5th Symposium on the Description and/or Comparison of English and Greek. Aristotle University, 11-32.

Schwartz, R. G. \& Terrell, B. Y. (1983). The role of input frequency in lexical acquisition. Journal of Child Language, 10, 57-64.

Scott, J. (2005). Creating opportunities to acquire new word meanings from text. In E. Hiebert \& M. Kamil (Eds.), Teaching and Learning Vocabulary: Bringing Research to Practice (pp. 69-91). Mahwah: Erlbaum.

Singleton, D. (2001). Age and Second Language Acquisition. Annual Review of Applied Linguistics, $21,77-89$.

Sunderman, G. \& Kroll, J. (2006). First language activation during second language lexical processing. Studies in Second Language Acquisition, 28, 387-422.

Takala, S. (1984). Evaluation of student's knowledge of English vocabulary in the Finnish comprehensive school. Reports of the Institute of Educational Research, 350. Jyvaskyla: Institute of Educational Research.

Waring, R. \& Takaki, M. (2003). At what rate do learners learn and retain new vocabulary from reading a graded reader? Reading in a Foreign Language, 15, 130-163.

Webb, S. (2007). Learning word pairs and glossed sentences: The effects of a single context on vocabulary knowledge. Language Teaching Research, 11, 63-81.

Xue, G. \& Nation, P. (1984). A university word list. Language Learning and Communication, 3, $215-$ 229.

Zhang, H., Huang, C. \& Yu, S. (2004). Distributional consistency: As a general method for defining a core lexicon. Paper presented at Language Resources and Evaluation. Lisbon, Portugal, 2004. 